\title{
Uma análise da estratégia nacional de desenvolvimento da Malásia
}

CLEOMAR GOMES

CLEMENS NUNES*

\begin{abstract}
An analysis of the national development strategy of Malaysia. This paper aims at studying Malaysia's national development strategy in the last three decades. Firstly, we will give emphasis to the country's economic planning development, its mediumterm and long-term plans, as well as Mahathir's political influence. Secondly, we will try to identify key elements in the Malaysian growth process, such as its exchange rate and current account policies, the participation of the government in the whole process and matters related to domestic savings and foreign direct investment. We will also talk about the 1997 financial crisis.

Keywords: economic development; economic growth; planning policy.

JEL Classification: O11; O21; O24; O53.
\end{abstract}

\section{INTRODUÇÃO}

O estudo do desenvolvimento econômico é um dos campos mais importantes da ciência econômica, seja pelo interesse que desperta em tentar explicar por que alguns países evoluíram mais que outros, ou pelo empenho em definir quais as estratégias e políticas são essenciais para a ascensão econômica dos países. Certamente, estes pontos se aplicam ao caso da Malásia. Apesar de apresentar várias características de subdesenvolvimento, o país tem alcançado um considerável sucesso em sua estratégia de crescimento ao longo das últimas décadas, saindo de uma situação agrária para uma condição de emergente de renda média. Conforme

\footnotetext{
* Respectivamente, Escola de Economia de São Paulo - Fundação Getulio Vargas (FGV-EESP). O autor agradece o apoio financeiro do CNPq. E-mail: cleomargomes@gvmail.br; e Escola de Economia de São Paulo - Fundação Getulio Vargas (FGV-EESP). E-mail: cvanunes@gvmail.br. Os autores agradecem os comentários e sugestões de Luiz Carlos Bresser-Pereira e de dois pareceristas anônimos. Submetido: Março 2006; Aprovado; Agosto 2007.
} 
dados do FMI, ${ }^{1}$ a Malásia contava, em 2005, com uma população de aproximadamente 26 milhões de habitantes e com um PIB per capita (baseado na paridade do poder de compra) de cerca de US\$ 11.000 , contra US\$ 8.500 para o caso brasileiro no mesmo ano. Já a taxa de inflação foi de 3\%, contra 5,69\% no Brasil.

A proposta deste artigo é analisar a estratégia de desenvolvimento nacional da Malásia nos últimos trinta anos. Procuraremos caracterizar o planejamento econômico do país no período em questão, enfatizando seus planos de médio e longo prazos. Também abordaremos a importância da influência política de Mahathir e tentaremos identificar os elementos determinantes para o crescimento malaio. Sobre este último tópico, trataremos de aspectos macroeconômicos importantes tais como a taxa de câmbio, a conta corrente, a crise financeira de 1997, a participação estatal no planejamento do desenvolvimento do país, o investimento estrangeiro e a poupança doméstica.

$\mathrm{O}$ argumento defendido neste artigo é que a evolução econômica de um país passa necessariamente por uma clara estratégia de desenvolvimento com a participação do Estado e da sociedade. O intuito é colaborar com a discussão acerca do tópico no Brasil, com vistas à formulação de uma estratégia nacional para o nosso desenvolvimento econômico. Como já dito, no caso da Malásia, este processo é composto por planos nos horizontes de curto, médio e longo prazos. Apesar de alguns problemas de cunho étnico e de uma ênfase insuficiente na universalização da educação, o país tem obtido sucesso no seu crescimento econômico e na diminuição da incidência de pobreza da população.

Além desta introdução, o artigo tratará, na segunda seção, do conceito de estratégia nacional de desenvolvimento. A terceira seção analisará o planejamento econômico da Malásia desde 1970. A seção seguinte tratará de elementos determinantes para o sucesso do crescimento malaio. A quinta seção concluirá o artigo.

\section{O CONCEITO DE ESTRATÉGIA NACIONAL DE DESENVOLVIMENTO}

Sendo o desenvolvimento econômico um fenômeno próprio do capitalismo, os primeiros estudos acerca do tema surgem com a ascensão ao poder desse modo de produção e levantam discussões sob vários prismas teóricos. ${ }^{2}$ Do ponto de vista clássico, a livre concorrência e o mecanismo de preços asseguram o crescimento equilibrado. Trabalho e capital deslocam-se dos setores da economia mais desenvolvidos para aqueles mais atrasados e, assim, neutralizam a correção automática

\footnotetext{
${ }^{1}$ http://www.imf.org/external/pubs/ft/weo/2006/02/data/index.aspx.

${ }^{2}$ Além das teorias aqui descritas, ainda podem ser citados os estudos de Malthus, sobre a relação entre população e crescimento econômico, e de Ricardo, acerca dos retornos decrescentes. Por outro lado, devem também ser lembrados a teoria marxista do desenvolvimento capitalista, as teorias desenvolvimentistas, como o big push, e os estudos das teorias da dependência, estruturalista e institucionalista (Cypher \& Dietz, 1997).
} 
de qualquer tendência de desequilíbrio (Kaldor, 1957). O prisma neoclássico segue essa mesma linha e apenas dá mais ênfase ao progresso tecnológico, como o modelo de crescimento de Solow, ou agrega a questão das idéias, como os modelos de crescimento endógeno. Mas o cerne da discussão continua o mesmo: microfundamentação e comportamento maximizador dos agentes econômicos num ambiente perfeitamente competitivo (Jones, 2000). De acordo com Kaldor (1957), se essa doutrina fosse correta, o desenvolvimento econômico poderia ser justificado por uma política do tipo laisser-faire. Contudo, tal argumentação possui limitações ao não levar em conta pontos importantes como, por exemplo, barreiras à entrada e o fato de muitos serviços essenciais (educação, saúde, justiça, sistema monetário etc.) não serem fornecidos adequadamente pela iniciativa privada.

Kuznets $(1981 ; 1985 ; 1986)$ define crescimento como a capacidade de um país de fornecer à sua população bens econômicos cada vez mais diversos. Para o autor, tal capacidade depende de tecnologia e adaptações institucionais e ideológicas capazes de causar uma rápida transformação estrutural. Tal transformação inclui a passagem do setor agrícola para os setores industriais e de serviços, a urbanização da sociedade e um papel crescente da educação formal. Como conseqüência, são observados aumentos no produto per capita, na produtividade e no comércio internacional. Por fim, cresce em relevância o papel do Estado em todo o processo.

A importância da participação estatal também é destacada por Bresser-Pereira (2006: 209), que define desenvolvimento econômico como sendo "o processo histórico de crescimento sustentado da renda por habitante visando à melhoria do padrão de vida da população de um determinado Estado Nacional”. Para que o processo aconteça, devem ser introduzidos novas técnicas de produção e de organização empresarial, incentivos à busca de novos produtos e mercados e estímulo a um aumento significativo da taxa de acumulação de capital. É neste estágio inicial que a participação estatal se torna essencial, principalmente em economias com poupança insuficiente. Numa etapa posterior, com o crescimento do sistema bancário e do mercado de capitais, o financiamento passa a ser feito por meio destas instituições, seja por via direta ou por intermediação financeira. Bresser-Pereira destaca, ainda, que esse financiamento deve ser substancialmente por intermédio de poupança interna, seja por meio de reinvestimento das empresas ou do financiamento estatal e/ou bancário. Os riscos de uma estratégia de crescimento com poupança externa originam-se das violentas flutuações da oferta destes recursos, bem como de condições de financiamentos (custos e prazos) incompatíveis com a natureza dos investimentos que, geralmente, são de prazos mais alongados e possuem retorno financeiro incerto.

O desenvolvimento econômico tem uma finalidade clara, conforme definição do parágrafo anterior: melhorar o padrão de vida da população. É função do Estado, como instrumento de ação coletiva da sociedade, dar plenas condições para que o processo aconteça e, também, prover segurança, liberdade e justiça social. Desta forma, a definição de uma estratégia de desenvolvimento deve ser entendida no contexto da ação do Estado Nacional no provimento de suas atribuições. Do 
ponto de vista ético, tal estratégia não pode ser considerada como o único objetivo governamental, mas sim de maneira articulada com as outras metas. Por exemplo, a evolução econômica de um país pode ser injusta socialmente, concentrando renda e oferecendo poucas oportunidades aos cidadãos com menor instrução (Bresser-Pereira, 2006). Como resultado, o prazo para que os benefícios do crescimento atinjam estas pessoas pode ser muito longo, o que pode levar à necessidade de criação de mecanismos compensatórios para atenuar possíveis problemas sociais. Além disso, a ampliação do padrão de vida da população depende não só da elevação do nível de investimento mas também de sua composição, ou seja, depende de um aumento da eficiência na alocação dos recursos.

Esta perspectiva sobre o papel do Estado no processo histórico de desenvolvimento possui peculiaridades próprias, quando comparada às perspectivas neoclássica e neo-institucionalista. Naquela, o Estado é tratado como uma "caixa-preta" e seu funcionamento interno não é objeto de estudo da análise econômica. Já na perspectiva neo-institucionalista de North (1981), reconhece-se a importância estatal no processo, mas desde que sua presença seja bastante restrita à proteção dos direitos individuais, das pessoas e das propriedades, além da ênfase aos contratos privados. Como campo de batalha entre grupos interessados em sua capacidade de gerar rendas, o papel governamental, segundo North, deve ser reduzido para evitar o efeito deletério da ação de rentistas sobre a economia. Além disso, mecanismos burocráticos devem ser substituídos por mecanismos de mercado sempre que possível.

Para North (2005), se o crescimento econômico fosse somente uma função de aumento no estoque de conhecimento e tecnologia, o futuro do bem-estar da raça humana estaria garantido. Contundo, quando levamos em consideração a complexa interação entre consciência e desenvolvimento das culturas, tal garantia inexiste. As diversas formas de desenvolvimento das crenças (instituições, organizações, políticas, resultados) já levaram tanto a um bem-estar econômico sem precedentes em alguns locais como também a desastres e miséria humana em outros.

Indubitavelmente, esta visão captura um aspecto importante do funcionamento de Estados onde as atividades de rent-seeking ou corrupção são por vezes dominantes. Mas a solução não é reduzir ao mínimo o único instrumento de ação que a nação dispõe para promover seu desenvolvimento, e sim tratar de reduzir o rent-seeking e a corrupção. Nos países periféricos, com graves tensões sociais, e por vezes étnicas como no caso malaio, a presença do Estado é importante para encontrar o equilíbrio nestes conflitos, que podem ser até mesmo exacerbados pelos mecanismos de mercado.

\section{O PLANEJAMENTO DO DESENVOLVIMENTO DA MALÁSIA}

A Federação da Malásia foi formada, em 1963, com a adição de Sarawak e Sabah (ex-Norte-Bornéu Britânico) à Federação da Malaya. Antes da formação do país, a Malásia Peninsular (ou Malásia do Oeste) já era composta por três segmen- 
tos étnicos principais: os Malays mulçumanos ( $\pm 60 \%$ da população); os chineses ( $30 \%$ da população) e os indianos $( \pm 10 \%$ da população). Com a adição das duas outras províncias (Sarawak e Sabah), a diversidade étnica do novo país aumentou consideravelmente. Os Borneans nativos, juntamente com os Malays e outros grupos indígenas, passaram a ser classificados como Bumiputera (King, 1988).

O Primeiro Plano da Malásia (1966-1970) foi o responsável pela integração do planejamento das três regiões componentes do país. A meta era a criação de um ambiente em que todos os grupos étnicos da nação fossem contemplados com a criação de maiores oportunidades de emprego e com a melhoria nas distribuições de renda e de riqueza. Mas a política de desenvolvimento escolhida era do tipo laissez-faire, com forte ênfase no desenvolvimento da indústria de substituição de importações. Esta estratégia propiciou um crescimento industrial do país a uma taxa média de 17,5\% entre os anos de 1959 e 1968 (Jomo, 1990). Contudo, houve escassez de postos de trabalho, a taxa de desemprego elevou-se de 6\% em 1965 para 7,3\% em 1970 e o programa foi amplamente ineficaz no quesito distribuição de renda e riqueza $(\operatorname{Lim}, 1983) .^{3}$

Isso resultou em desequilíbrios entre os grupos étnicos componentes da nação malaia, culminando com uma grave revolta racial em 1969. Ficou clara, também, a fragilidade da aliança governamental entre os Malays, chineses, indianos e Borneans não-mulçumanos, além da insatisfação da classe baixa malaia composta predominantemente da etnia Bumiputera (King, 1988).

\section{A nova política econômica}

Para superar os problemas acima relatados, o governo implementou o primeiro plano de desenvolvimento de longo prazo, denominado Nova Política Econômica (NPE), formalmente instituído no Segundo Plano da Malásia (1971-1975) e projetado para vigorar por duas décadas. A NPE passou a enfatizar uma industrialização acelerada com destaque para dois tipos de indústrias exportadoras: aquelas baseadas no processamento de commodities primárias e aquelas localizadas nas Zonas de Livre-comércio (ZLC). Como estavam geralmente fixadas em regiões de salários mais baixos e eram muito intensivas em trabalho, as ZLC possibilitaram à Malásia sediar empresas estrangeiras de montagens de equipamentos eletrônicos a baixo custo para exportá-los em seguida (Jomo, 1990).

Para encorajar o aumento de um proletariado urbano educado, o governo institucionalizou o "Malay" como língua oficial, expandiu o acesso à educação pública e aos programas especiais para a população e também investiu fortemente

\footnotetext{
${ }^{3}$ Embora a Unidade de Planejamento Econômico (UPE), vinculada diretamente ao Gabinete do Primeiro-Ministro e com o objetivo de gerenciar e monitorar as agências de desenvolvimento do país, tenha sido criada em 1961, o planejamento econômico do país iniciou-se nos idos de 1950, quando foi lançado o Primeiro Plano de Desenvolvimento Qüinqüenal do Estado da Malásia (1956-1960).
} 
em treinamento técnico e vocacional, especialmente por meio do MARA,${ }^{4} \mathrm{o}$ ministério malaio responsável pela promoção social dos povos indígenas. Também foram criadas cotas étnicas para os trabalhadores "Malay" (Ritchie, 2004).

Figura 1

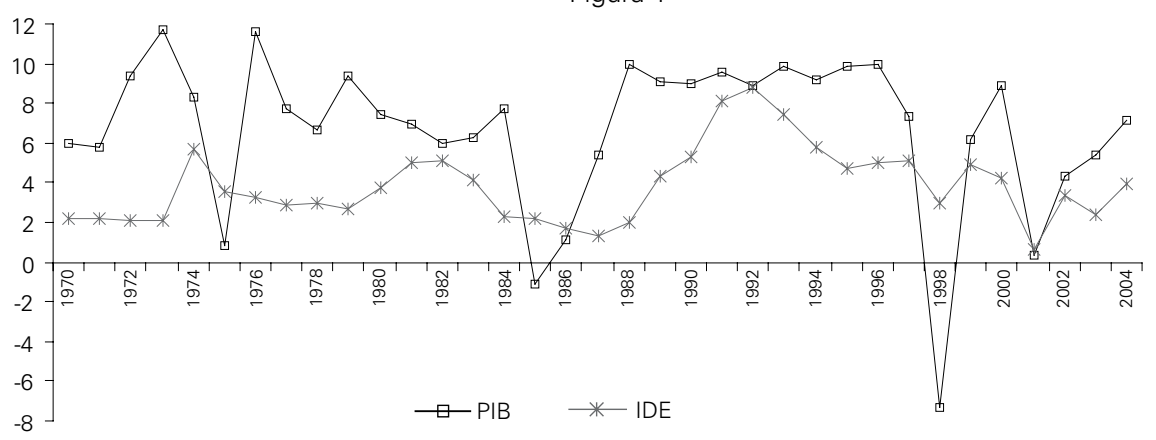

Fonte: World Development Indicators.

Mesmo com o impacto da recessão mundial na economia malaia entre $1974 \mathrm{e}$ 1975, a Figura 1 mostra que, nos cinco primeiros anos de implementação da NPE, o crescimento econômico foi de 7,0\% em média e, se não levarmos em conta os dados de 1975 , a média passa para $8,2 \%$, excedendo a meta original de $6,8 \%$. Destaque também para o crescimento das importações (Figura 2), indicando que o país realmente importava primeiro para depois exportar, e para a participação do investimento público nos cinco primeiros anos da NPE, que aumentou 17,6\% ao ano em média, contra $1,9 \%$ no primeiro plano qüinqüenal. Por outro lado, apesar da ênfase dada ao investimento direto estrangeiro, este teve um aumento médio de cerca de 3\% (como proporção do PIB) na mesma época (Lim, 1983).

\section{Figura 2}

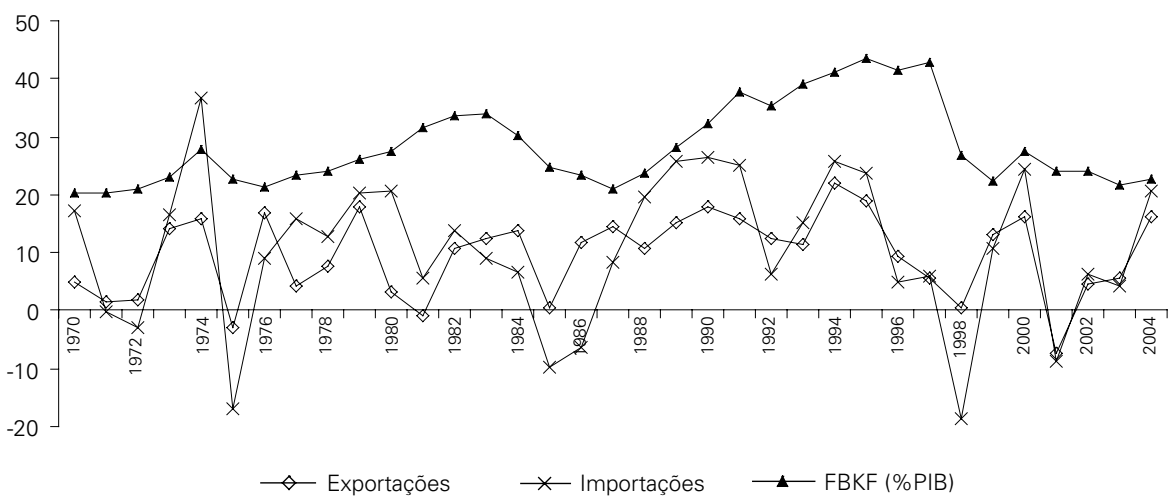

Fonte: World Development Indicators.

${ }^{4}$ MARA: Majlis Amanah Rakyat. Em inglês: Council of Trust for the Indigenous People. 
O Terceiro Plano da Malásia (1976-1980) deu seqüência à implementação dos objetivos da NPE. A estratégia adotada foi similar ao segundo plano, ou seja, reduzir a incidência da pobreza e reestruturar a sociedade por meio do crescimento, ao invés de uma estratégia redistributiva (Lim, 1983). O crescimento econômico foi de 7,3\% em média (Figura 1), graças ao aumento da formação bruta de capital fixo e, conseqüentemente, das exportações. A incidência de pobreza no país diminuiu de cerca de 50\% em 1975 para cerca de 30\% em 1980. A taxa de alfabetização também continuou em sua trajetória ascendente (Figura 3).

Assim, a década de 1970 destacou-se pela predominância da participação estrangeira nas várias indústrias de alta tecnologia localizadas nas ZLC malaias. Esta característica somente começou a ser mudada em meados da década de 1980, quando cresceram as oportunidades de encadeamento para trás à medida que as empresas internacionais começaram a utilizar mais a subcontratação de empresas malaias. Contudo, o controle do capital doméstico nas ZLC continuou muito pequeno, significando que o desenvolvimento estratégico das indústrias nacionais ainda estava restrito às condições impostas pelo capital internacional (Rasiah, 1993).

Figura 3

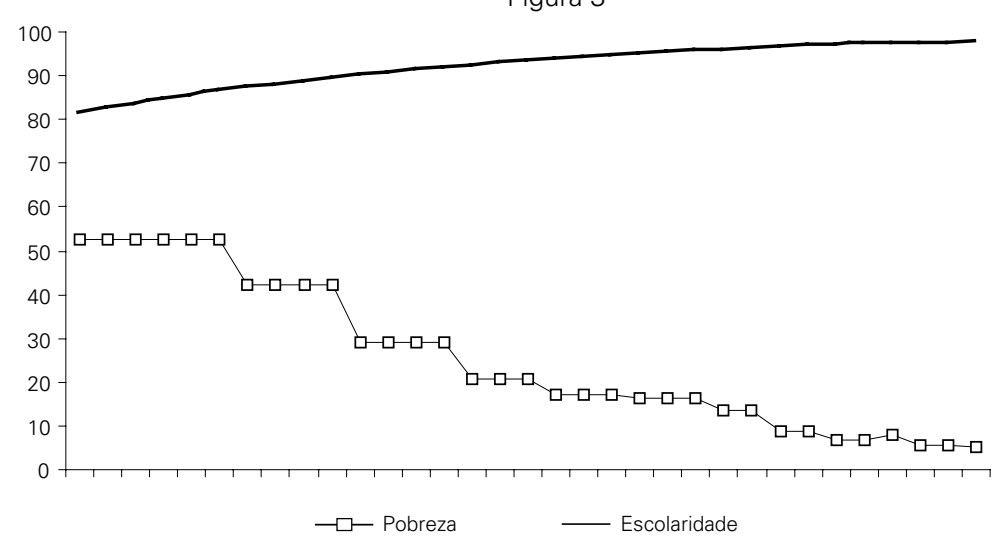

Fonte: Escolaridade: Pobreza: Abhayaratne (2004); World Development Indicators.

\section{A década de 1980 e a gestão de Mahathir}

O Quarto Plano da Malásia coincidiu com a ascensão ao poder da figura polêmica de Mahathir bin Mohamad como Primeiro-Ministro da Malásia, cuja permanência no cargo estendeu-se até 2003. Mahathir é visto por alguns observadores como o personagem central da rápida modernização do país. Sem dúvida, seu feito mais notável foi sua habilidade em estabelecer um acordo nacional básico entre as diversas etnias, com o fortalecimento de uma classe média nacional, independente da tradicional elite chinesa. Como defensor do papel do Estado no processo de desenvolvimento, a meta de Mahathir era transformar a Malásia num NIC (Newly Industrialized Country) sob a liderança de empreendimentos capitalistas Bumiputera. Para isso, ele priorizou inicialmente a chamada Política de 
Visão para o Leste (Look East Policy), ${ }^{5}$ onde o exemplo a ser seguido era a modernização japonesa (Jomo, 1993).

Desde sua passagem pelo Ministério do Comércio e Indústria no final da década de 1970, Mahathir tentou fomentar a industrialização pesada direcionada à exportação. Seu argumento era que o país havia se baseado muito, e com conseqüências adversas, na substituição de importação leve, no processamento de matériaprima e na exportação leve de manufatura para o crescimento industrial. Ainda na década de 1970, Mahathir fundou o HICOM (Corporação de Indústrias Pesadas da Malásia) para coordenar e dar suporte ao seu projeto. Em 1981, Mahathir passou a responsabilidade do HICOM de seu antigo Ministério para seu Gabinete do Primeiro-Ministro. Com este ato ele colocou a máquina governamental para planejar o desenvolvimento de seletas indústrias pesadas, impulsionando os projetos ligados às indústrias de cimento, aço e automobilísticas (Jomo, 1990). Contudo, a crise econômica mundial do período teve um grande impacto na economia malaia, principalmente na indústria exportadora de eletrônicos (Figura 2). Houve queda considerável do PIB (Figura 1), chegando a ser negativo em 1985, com conseqüência imediata no aumento das taxas de desemprego do país (Tabela 1).

Em 1986, quando estava em vigor o Quinto Plano Malaio, o governo publicou o chamado Industrial Master Plan (IMP), cujo intuito foi oferecer uma análise dos problemas estruturais associados ao setor manufatureiro (primeiramente com a substituição de importações e posteriormente com as indústrias pesadas) e traçar novas metas para a industrialização do país. Para o relatório do IMP, a Malásia estava atrasada em seu processo de desenvolvimento porque o sucesso alcançado na expansão da produção de matérias-primas foi suficiente para financiar as necessidades de importação do país e enfraqueceu, assim, a necessidade de um novo paradigma em sua industrialização. Além disso, o IMP detectou que a estrutura industrial malaia estava caracterizada por vários desequilíbrios, sendo um deles o fato de o setor manufatureiro possuir poucas indústrias intensivas em trabalho, principalmente trabalho mais qualificado.

Tabela 1: Emprego por setor (\% do emprego total) e taxa de desemprego total

\begin{tabular}{lccccccc}
\hline & 1976 & 1980 & 1985 & 1990 & 1995 & 2000 & 2004 \\
\hline Emprego - Agricultura & 43,6 & 37,2 & 30,4 & 26,0 & 20,0 & 18,4 & 14,8 \\
\hline Emprego - Indústria & 20,9 & 24,1 & 23,8 & 27,5 & 32,3 & 32,2 & 30,1 \\
\hline Emprego - Serviços & 35,5 & 38,7 & 45,8 & 46,5 & 47,7 & 49,5 & 55,1 \\
\hline Taxa de Desemprego Total & - & 5,6 & 6,9 & 5,1 & 3,1 & 3,0 & 3,5 \\
\hline
\end{tabular}

Fonte: Athukorala \& Menon (1997) para 1976 e World Development Indicators para o restante.

Nota: Os dados de agricultura para 1976 também incluem o emprego dos setores de pesca e florestal.

\footnotetext{
${ }^{5}$ Mahathir também instituiu políticas polêmicas como uma meta demográfica para o país de 70 milhões de malaios a ser alcançada até 2100. Também lançou um esboço de política agrícola (National Agricultural Policy), um programa de melhoria das relações entre os setores públicos e privados e um programa de privatizações (Jomo, 1990).
} 
Acerca do setor de substituição de importações, que ainda continuava atuante mas não como principal estratégia de desenvolvimento do país, o IMP concordava que ele estava extremamente protegido, o que levava à proteção de altos lucros e ineficiência às custas dos interesses do consumidor. Já o setor exportador estava dominado pelas indústrias de produtos elétricos e eletrônicos e pelas indústrias têxteis e de vestuário. Por exemplo, estes dois setores eram responsáveis, em 1983, por $65 \%$ das exportações de manufaturas do país, e somente a indústria de semicondutores respondia por $41 \%$. Todavia, ele era limitado pois as manufaturas de componentes eletrônicos, por exemplo, trabalhavam com montagens simples e eram propriedades de transnacionais, cujo maior interesse pela Malásia residia nos baixos salários e incentivos fiscais existentes no país. O efeito colateral de tal característica era a falta de encadeamento entre as indústrias localizadas no país, especialmente entre aquelas localizadas dentro e fora das Zonas de LivreComércio (Jomo, 1990).

Figura 4

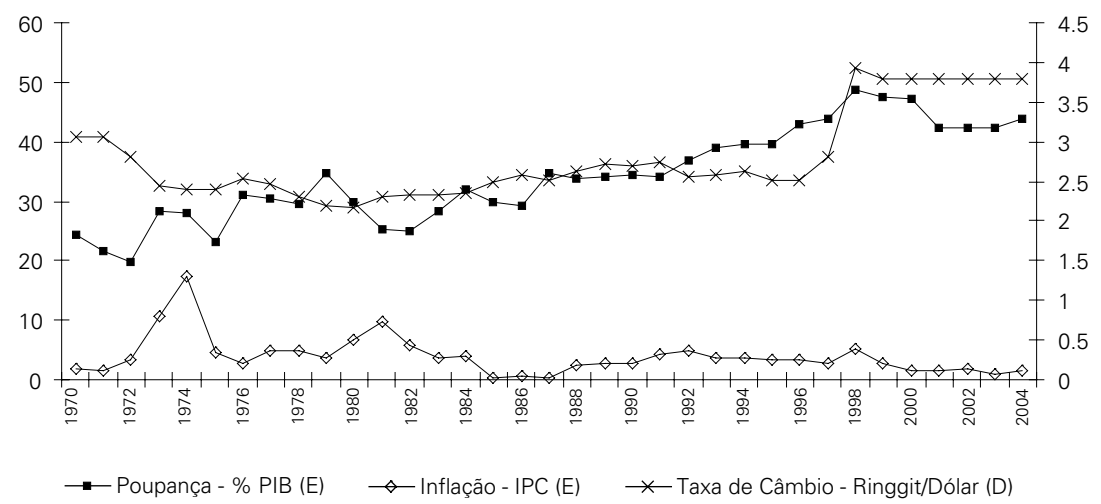

Fonte: World Development Indicators.

Para superar os entraves detectados pelo IMP, o governo objetivou uma maior liberalização do investimento estrangeiro e um maior incentivo à utilização de materiais locais como insumos. Também procurou-se aumentar os incentivos ao setor exportador, com concentração em um pequeno grupo de indústrias previamente selecionadas mas com grande potencial. Mas a proposta mais interessante foi a redução do protecionismo excessivo dado ao setor de substituição de importações (Jomo, 1990). Por fim, o investimento em capital humano também foi algo que ganhou importância com a implementação do IMP (Lucas \& Verry, 1999).

A colocação em prática do relatório do IMP provocou uma recuperação considerável do setor manufatureiro malaio. Uma das razões para tal foi o realinhamento cambial da metade de 1980, resultando numa depreciação considerável do Ringgit (Figuras 4 e 5) e diminuindo custos de produção, especialmente custo de trabalho. Desregulação e novos incentivos de investimentos também contribuíram 
para o ressurgimento do investimento em manufatura, crescimento do setor, exportações e emprego (Edwards \& Jomo, 1993).

Figura 5

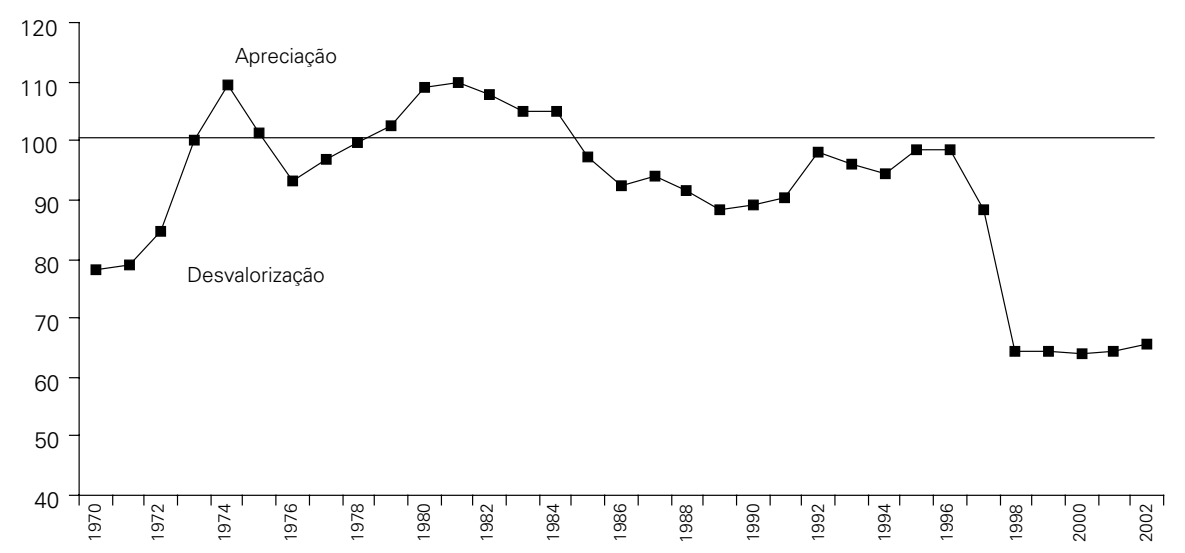

Fonte: World Development Indicators.

Apesar da forte recessão da metade da década de 1980, dados do World Development Indicators mostram que a Malásia manteve um crescimento econômico médio de $6,15 \%$. Já a média de crescimento da poupança bruta sobre o PIB, muito importante para o desenvolvimento econômico do país, ficou em 30,6\%, contra $27 \%$ na década anterior (Figura 4). Na segunda metade da década as exportações e importações recuperaram-se consideravelmente (Figura 2). Outro fato interessante foi o crescimento em importância do setor de serviços, principalmente para geração de empregos (Tabela 1).

\section{A nova política de desenvolvimento e o plano Vision 2020}

Apesar do crescimento malaio observado nas duas primeiras décadas, muito ainda devia (e deve) ser feito para o pleno desenvolvimento do país, o que está em linha com a discussão feita anteriormente de que o processo de desenvolvimento é algo demorado. Reconhecendo a necessidade de mais avanços, o governo aproveitou a substituição da NPE pela Nova Política de Desenvolvimento (NPD), ocorrida em 1991, para iniciar a transformação de uma economia intensiva em trabalho para uma produção mais intensiva em capital e tecnologia. As prioridades redistributivas da NPE deram lugar às prioridades de desenvolvimento da NPD que, embora com ênfases distintas, incluíram esforços simultâneos para aumentar: 1) a oferta de trabalho; 2) o nível técnico da força de trabalho local; 3) o nível tecnológico das empresas estrangeiras e nacionais; 4) a participação nacional nas empresas exportadoras estrangeiras (Ritchie, 2004). Dado o sucesso do planejamento anterior, o Sexto Plano da Malásia reforçou esta meta para um crescimento econômico de 7,5\% (Von Der Mehden, 1992). E para o período 1990-1995 este 
objetivo foi superado facilmente, dado o crescimento econômico médio de 9,4\% ao ano (Figura 1).

A NPD também serviu como base para a primeira década de vigor do plano de longo prazo da Malásia, denominado Vision 2020 e lançado em 1991. Este vigorará por 30 anos e tem a ambiciosa meta de desenvolver completamente o país até o final do período proposto. Já a segunda parte do Vision 2020 ficou a cargo do plano decenal denominado "Política de Visão Nacional", lançado em 2001, com estratégias similares às anteriores: desenvolvimento econômico equilibrado, erradicação da pobreza, fortalecimento do investimento doméstico, mais ênfase ao investimento direto externo. O intuito é mudança para uma economia baseada no conhecimento e na economia da informação. Com esta estratégia, o país pretende alcançar taxas de crescimento sustentáveis no longo prazo e quadruplicar o PIB num prazo de 20 a 25 anos. Contudo, este nível ainda está longe de ser alcançado. Há vários elementos ausentes ou deficientes como, por exemplo, infra-estrutura (física, institucional e educacional), sistema financeiro, pesquisa e desenvolvimento, dentre outros (Mustapha \& Abdullah, 2004).

\section{ELEMENTOS DA ESTRATÉGIA MALAIA DE DESENVOLVIMENTO}

Nas seções anteriores procuramos caracterizar a estratégia de desenvolvimento da Malásia sem nos atermos à identificação explícita dos elementos determinantes para o sucesso do crescimento do país. Também não especificamos aqueles elementos que não deram certo e tiveram de ser repensados. Tentaremos avançar mais um pouco nestes tópicos. Os pontos a serem discutidos são: aspectos macroeconômicos importantes como, por exemplo, a taxa de câmbio, a conta corrente e crise financeira do final da década de 1990, a participação estatal no planejamento do desenvolvimento do país e a questão do investimento estrangeiro e da poupança doméstica.

\section{Aspectos macroeconômicos da economia malaia}

A conta corrente é um medidor importante para guiar as decisões econômicas de formuladores de políticas e agentes privados. Se, por um lado, déficits temporários nas transações correntes podem representar uma simples realocação de capital entre os entes econômicos, por outro, déficits persistentes necessitam de uma intervenção governamental rígida. De fato, contas correntes muito negativas tendem a não ser muito persistentes e poucos países mantêm tal política por mais de cinco anos seguidos (Edwards, 2002). Isso acontece porque tal problema tende a aumentar as taxas de juros domésticas em relação às internacionais e, desta maneira, impõem um peso excessivo às futuras gerações. A razão está na acumulação da dívida, que implicará mais pagamentos de juros e, conseqüentemente, em queda do nível de vida da população. O resultado é desequilíbrio macroeconômico do país, cuja solução passa por uma desvalorização cambial e/ ou um aperto nas demais políticas macroeconômicas. Por outro lado, caso esses 
desequilíbrios externos não sejam solucionados, eles poderão ser cruciais na propagação de crises financeiras.

Se por um lado a abertura malaia ao comércio internacional propiciou ao país o acesso a novos mercados, por outro lado esta abertura o deixou altamente vulnerável a choques de termos de troca que resultaram em profundas recessões em meados das décadas de 1970 e 1980 . Além disso, houve períodos de déficits fiscais consideráveis, que colaboraram para uma desestabilização ainda maior.

Como resultado do financiamento de seu desenvolvimento, o governo malaio passou a década de 1980 incorrendo em pesados empréstimos internacionais, apesar de também se apoiar em menor grau em financiamento interno. Como efeito direto de tais empréstimos e também das altas taxas de juros domésticas (Figura 6), o influxo de capital externo foi considerável, principalmente a partir da segunda metade da década de 1980 (Figura 1). Para manter a situação econômica sob controle, a solução encontrada foi uma política monetária restritiva e um gerenciamento da taxa de câmbio (Figura 4), de forma a gerar baixos níveis inflacionários (Lucas \& Verry, 1999).

Figura 6

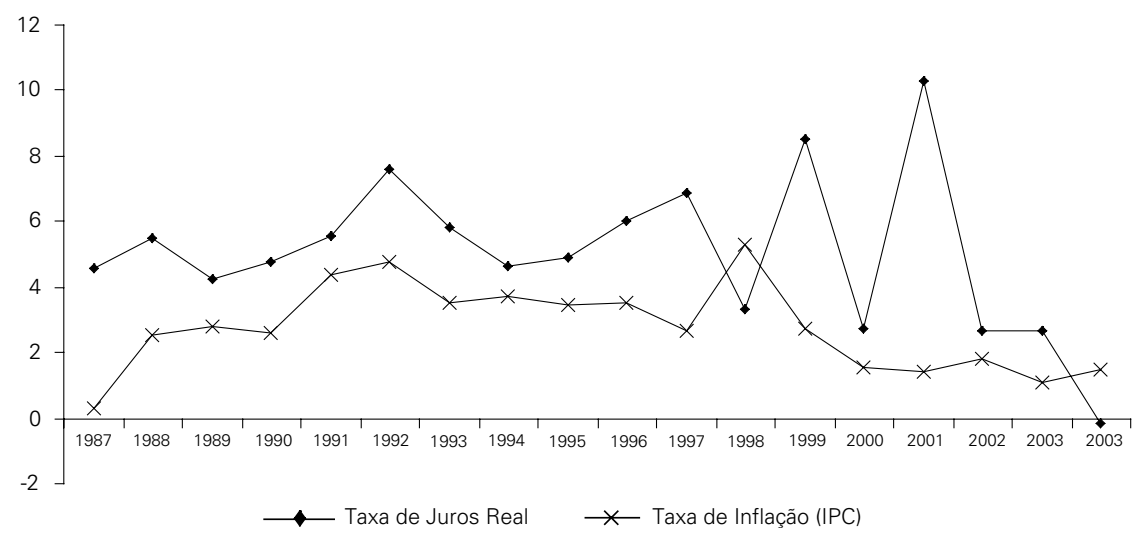

Fonte: World Development Indicators.

Isso provocou um superávit da balança de pagamentos que, por sua vez, adiou quaisquer ajustes maiores na taxa de câmbio. Esta se apreciou substancialmente na metade da década de 1980 (Figura 4) para, posteriormente, iniciar um processo de diminuição. Como resultado da política monetária restritiva e da apreciação do Ringgit, a inflação permaneceu bem controlada (Figura 4), exceção para o processo inflacionário relacionado ao primeiro choque do petróleo. Note que a apreciação cambial também provocou um comportamento errático das exportações malaias, que somente começaram a mostrar claros sinais de recuperação após a depreciação cambial da metade da década de 1980 , e durou até a crise de $1997 .{ }^{6}$

\footnotetext{
${ }^{6}$ Esta crise financeira não afetou somente a Malásia. Os outros três países (Indonésia, Filipinas e
} 


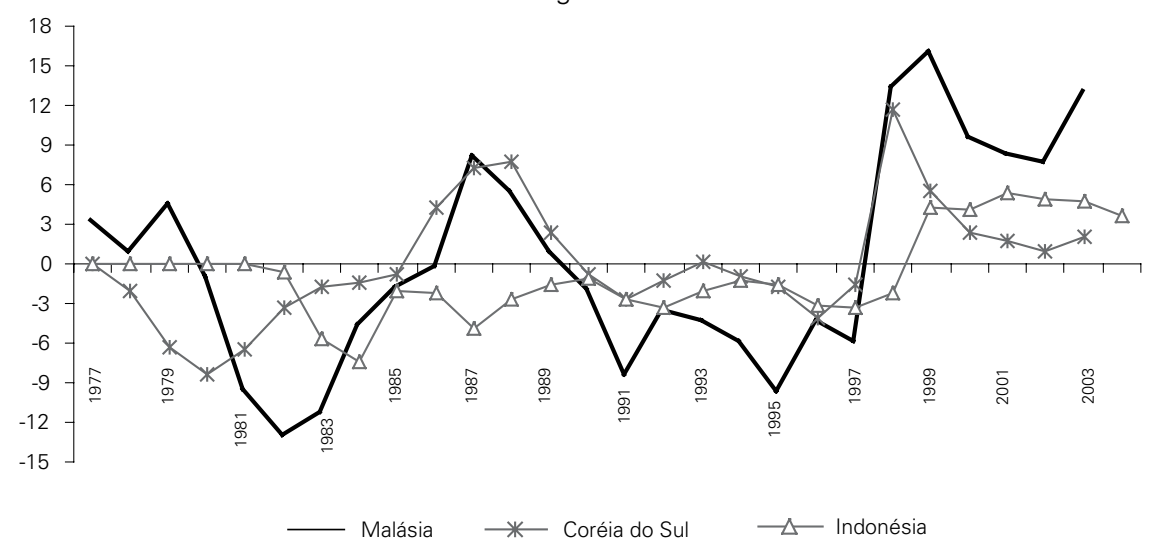

Fonte: World Development Indicators.

O rápido crescimento econômico da Malásia observado entre 1990 e 1996 (Figura 1) foi bruscamente afetado pela crise financeira que assolou todo o Sudeste Asiático entre 1997 e 1998. Isso aconteceu mesmo com o país tendo os fundamentos macroeconômicos em ordem antes do início da tensão, com exceção do grande déficit de conta corrente (Figura 7) que, mesmo assim, era tido como aceitável. O atrelamento virtual do Ringgit (a moeda malaia) e outras moedas dos paises asiáticos ao dólar americano (Figuras 4 e 5) desde a metade de 1980 havia melhorado a competitividade exportadora da região até o iene japonês começar a depreciar-se em meados de 1995. O colapso da Tailândia e o efeito contágio exacerbado pelo comportamento de manada resultaram no fim da bolha no preço dos ativos da região (Jomo, 1998). Isso resultou na perda de confiança dos investidores e consumidores, causando um colapso no investimento e consumo privados.

Para o caso específico malaio, houve queda do PIB no valor de 7,4\% em 1998 (Figura 1), culminando também com um aumento da taxa de pobreza do país em 1999 (Figura 3). Quedas maiores aconteceram na Formação Bruta de Capital Fixo e nas Importações, cujos valores foram os menores entre 1970 e 2002 (Figura 2). Além disso, houve uma grande reversão na política econômica do país. Após o início da crise, o governo optou por uma política contrária à intervenção liberal apregoada pelo FMI e implementou um controle seletivo de saída de capitais estrangeiros. Esta estratégia fez com que diminuíssem os ataques especulativos à moeda, dando condições ao Banco Nacional da Malásia de promover uma redução da taxa de juros e restabelecer a atuação da política monetária. O controle de

Tailândia) componentes da Association of South East Asian Nations, o chamado ASEAN4, também passaram por dificuldades semelhantes em função do fluxo massivo de capital estrangeiro, mesmo este sendo primordialmente utilizado na importação de bens de capital (Baharumshah, Lau \& Fountas, 2003). A título de comparação, os países da América Latina também receberam inversões vultosas de capital estrangeiro que, ao contrário dos ASEAN4, foram largamente utilizados no financiamento de consumo público e privado. 
capitais foi subseqüentemente reduzido para o hot money. ${ }^{7}$ Entretanto, como este capital já havia deixado a Malásia, a ação governamental acabou punindo aqueles investidores que tinham mostrado algum tipo de lealdade ao país. O total abandono desta intervenção mais rígida no mercado de capitais aconteceu em 1999, apesar de uma taxação à saída ter permanecido por mais tempo (Ritchie, 2004).

A manutenção de uma taxa de câmbio competitiva sempre foi um elementochave para a Malásia, dada a sua estratégia de crescimento baseada em exportações. Desta forma, o Banco Central malaio atua de forma a evitar uma apreciação da moeda e a reduzir sua volatilidade, para que seja criado um ambiente econômico previsível para os exportadores. Embora esta política tenha sido implementada consistentemente de forma de facto, ela contrasta fortemente com o modo de jure da política cambial. No período de 1986 a 2000, o país teve quatro regimes cambiais: flexibilidade limitada (jan./1986 a fev./1990), rigidez cambial (mar./1990 a nov./1992), regime de bandas (dez./1992 a set./1998) e atrelagem ao dólar americano (set./1998 a dez./2000). De todo modo, a Figura 5 mostra que o país já vinha trabalhando com uma taxa de câmbio real desvalorizada desde a metade da década de 1980, sendo esta política intensificada após a crise financeira da década de 1990. Com tal estratégia, a Malásia pôde recuperar sua economia rapidamente, com crescimento médio das exportações de $12 \%$ no período de 1999 a 2000 . Entre os países asiáticos, somente a Coréia apresentou desempenho superior, com exportações e PIB crescendo, respectivamente, 17,4\% e 9,7\% entre 1999 e 2000 (Tabela 2).

Tabela 2: Recuperação das economias do Sudeste Asiático pós-crise de 1997

\begin{tabular}{c|c|c|c|c}
\hline \multirow{2}{*}{ País } & \multicolumn{2}{|c|}{ Período: 1998} & \multicolumn{2}{c}{ Período: 1999-2000 } \\
\cline { 2 - 5 } & $\begin{array}{c}\text { Crescimento } \\
\text { Exportações }\end{array}$ & $\begin{array}{c}\text { Crescimento } \\
\text { do PIB }\end{array}$ & $\begin{array}{c}\text { Crescimento } \\
\text { Médio das } \\
\text { Exportações }\end{array}$ & $\begin{array}{c}\text { Crescimento } \\
\text { Médio do PIB }\end{array}$ \\
\hline Malásia & $-0,21 \%$ & $-7,37 \%$ & $11,87 \%$ & $5,85 \%$ \\
\hline Tailândia & $6,72 \%$ & $-10,17 \%$ & $10,42 \%$ & $4,59 \%$ \\
\hline Filipinas & $-21,03 \%$ & $-0,59 \%$ & $9,14 \%$ & $3,66 \%$ \\
\hline Coréia & $13,25 \%$ & $-6,69 \%$ & $17,42 \%$ & $9,71 \%$ \\
\hline Indonésia & $11,18 \%$ & $-13,01 \%$ & $-14,74 \%$ & $2,17 \%$ \\
\hline
\end{tabular}

Fonte: Hernandez \& Montiel (2003).

É importante mencionar que os países de melhor performance optaram por soluções radicalmente opostas nas políticas de integração com o mercado de capitais global. Enquanto a Malásia optou por menor flexibilidade, fixando a taxa de câmbio ao dólar americano e restringindo a movimentação de capitais, a Coréia

\footnotetext{
${ }^{7}$ Ativos capazes de se tornar líquidos rapidamente e se moverem rapidamente para dentro ou fora do país.
} 
privilegiou o aumento de sua integração com o mercado de capitais, flexibilizando a movimentação de sua moeda, mas sem atingir o extremo da flutuação pura. ${ }^{8}$

\section{O papel do Estado e a questão do investimento}

Destacamos, no início deste trabalho, a relevância do papel do Estado em todo o processo de desenvolvimento econômico de um determinado país. O Estado é o instrumento de ação coletiva da sociedade que dá o suporte necessário às iniciativas privadas e também atua diretamente em funções de planejamento, execução e correção de desvios de rota, além de sua função social. Nesta subseção apenas enfatizaremos mais este ponto, assim como a questão do investimento direto estrangeiro e da poupança doméstica.

$\mathrm{Na}$ descrição do planejamento do desenvolvimento da Malásia, vimos que a participação estatal se dá de forma muito atuante. Tal participação começa pela delineação dos planos de desenvolvimento, sejam eles de curto, médio ou longo prazos, e chega à resolução dos problemas étnicos e culturais da sociedade malaia, problemas estes ainda não resolvidos em sua totalidade. A figura do Estado tomou ainda maior relevância na gestão de Mahathir, pois foi ele que propiciou a entrada definitiva do país na estratégia de crescimento para a exportação. Como já salientamos, o ex-Primeiro-Ministro também foi responsável por alguns problemas de direcionamento de políticas de desenvolvimento como, por exemplo, a frustrada tentativa de fomento da industrialização pesada do país.

O Estado também tem sido importante na definição dos métodos de financiamento do desenvolvimento malaio. Não se pode negar a importância do investimento direto estrangeiro ao longo do planejamento econômico do país nas últimas décadas, como bem relatado na Figura 1. Mas este mesmo gráfico confirma o caráter cíclico do influxo de capitais internacionais. como relatado na segunda seção deste artigo. Houve três grandes paradas súbitas de capitais externos (em meados das décadas de 1970 e 1980, e a maior delas na crise financeira de 1997-1998), que não adentraram o país justamente quando a Malásia mais necessitava deles. Vimos que, na crise do final da década de 1990, a política adotada pelo país foi crucial para que sua recuperação fosse rápida e sustentada. Em resumo, poupança externa é importante, mas deve ser tratada com cuidado.

Tabela 3: Valores médios do investimento direto estrangeiro e poupança doméstica (\%PIB)

\begin{tabular}{ccccc}
\hline & $1970-1979$ & $1980-1989$ & $1990-1999$ & $2000-2004$ \\
\hline Investimento Direto Estrangeiro & 2,96 & 3,18 & 5,82 & 2,89 \\
Poupança Doméstica Bruta & 27,09 & 30,25 & 40,65 & 43,64 \\
\hline
\end{tabular}

Fonte: World Development Indicators.

\footnotetext{
${ }^{8}$ Para um maior aprofundamento sobre este tópico, o leitor pode referir-se a Mishkin (1999), Kaplan \& Rodrik (2001), Dornbusch (2001).
} 
Por outro lado, pudemos notar que, além do influxo de capitais externos, a Malásia tem contado cada vez mais com números consideráveis de poupança doméstica. Isso já fica claro na Figura 4, mas aqui comparemos as médias do investimento direto estrangeiro e poupança doméstica bruta (ambas como proporção do PIB). Os valores estão reportados na Tabela 3. Podemos notar que o influxo de capitais externos alcançou seu pico na década de 1990, em termos médios, e recuou nos primeiros anos da década vigente. Já a poupança doméstica bruta tem crescimento constante, já atingindo quase $50 \%$ do PIB. Isso é um bom indicativo da preocupação do país, ao longo de seu planejamento do desenvolvimento, em fomentar a poupança doméstica para seu crescimento econômico.

\section{CONSIDERAÇÕES FINAIS}

O objetivo deste artigo foi analisar a estratégia de desenvolvimento nacional da Malásia nos últimos 30 anos. Dentre outras questões, o trabalho abordou a questão do planejamento econômico do país, a passagem de um processo de substituição de importações para um crescimento direcionado às exportações e a influência política de Mahathir e sua tentativa de promover uma industrialização pesada. Em seguida, o artigo trouxe uma discussão relativa aos elementos determinantes para o sucesso do crescimento malaio. Entre eles, foram abordados aspectos macroeconômicos como, por exemplo, a taxa de câmbio, a conta corrente, a participação estatal no planejamento do desenvolvimento do país e a questão do investimento estrangeiro e da poupança doméstica. A crise financeira de 1997 também fez parte da discussão.

Certamente, o crescimento malaio neste período foi inegável e propiciou à Malásia a passagem de uma condição de país pobre e predominantemente agrário para um país industrializado. A estabilidade econômica do país, abertura ao comércio internacional e uma rápida acumulação de ativos são fatores que se mostraram importantes para essa transformação. Mas, indubitavelmente, o planejamento do desenvolvimento e a participação estatal foram cruciais. Em outras palavras, a estratégia de desenvolvimento traçada pelas autoridades políticas do país tem sido de extrema importância, apesar dos percalços e crises encontrados ao longo dos anos. A busca de oportunidades, representada pela crescente tendência de internacionalização da produção, tem sido largamente aproveitada pela Malásia, que tem se inserido no mercado internacional com muita competência.

Do ponto de vista social, houve melhorias consideráveis na diminuição da pobreza e na reestruturação da sociedade, de forma a eliminar a identificação de raça com função econômica e localização geográfica. Mas há muito a ser feito para que sejam alcançados os patamares ideais de uma nação desenvolvida.

Não há dúvida de que o crescimento econômico da Malásia é uma boa fonte de análise para a formulação de uma estratégia de desenvolvimento brasileira. Nos seus aspectos relevantes, ele mostra a importância da presença do Estado na mediação de um acordo nacional básico para apaziguar tensões sociais, na 
formulação de políticas definidas e articuladas com a sociedade, na sua atuação para promover o desenvolvimento com um grau mínimo de eqüidade. A meta do país é o pleno desenvolvimento até 2020 . Tal proposta é deveras ambiciosa, mas o simples fato de o país traçar uma meta e tentar alcançá-la já é algo bem interessante. Cabe ao Brasil iniciar uma rápida estratégia de desenvolvimento para não ser deixado para trás por mais um país asiático.

\section{REFERÊNCIAS BIBLIOGRÁFICAS}

ABHAYARATNE, A. (2004). "Economic Growth and Poverty Reduction: Lessons from the Malaysian Experience”. In: MARWAH, R. (ed). Comparative Perspectives on Asian Development: A View from South Asia, New Delhi, pp. 27-39.

ATHUKORALA, P. C. \& MENON, J. (1997). Export-led Industrialization, Employment and Equity: The Malaysian Case, mimeo.

BAHARUMSHAH, A. Z.; LAU, E. \& FOUNTAS, S. (2003). "On the Sustainability of Current Account Deficits: Evidence From Four ASEAN Countries.” Journal of Asian Economics, 14 (3), pp. 465-487.

BRESSER-PEREIRA, L. C. (2006). "Estratégia Nacional de Desenvolvimento”. Revista de Economia Política, 26(2), Abril-Junho.

CYPHER, J. M. \& DIETZ, J. L. (1997). The Process of Economic Development. New York: Routledge.

DORNBUSCH, R. (2001). “Malaysia: Was it Different?” NBER Working Paper 8325, Junho.

ECONOMIC PLANNING UNIT - PRIME MINISTER'S DEPARTMENT (2004). Development Planning in Malaysia. Disponível on Line: http.//www.epu.jpm.my.

EDWARDS, S. (2002). “Does the Current Account Matter?” In: EDWARDS, S. \& FRANKEL, J. A. (eds.). Preventing Currency Crises. Chicago: The University of Chicago Press.

EDWARDS, C. \& JOMO, K.S. (1993). "Policy Options for Malaysian Industrialisation”. In: JOMO, K. S. (ed.). Industrializing Malaysia: Policy, Performance, Prospects. New York: Routledge.

HERNANDEZ, L. \& MONTIEL, P. (2003). "Post-Crisis Exchange Rate Policy in Five Asian Countries: Filling the "Hollow Middle"?" Journal of the Japanese and International Economies 17(3), September, pp. 336-369.

JOMO, K. S. (1990). Growth and Structural Change in the Malaysian Economy. New York: St. Martin's Press.

JOMO, K. S. (1993). “Introduction”. In: JOMO, K. S. (ed.). Industrializing Malaysia: Policy, Performance, Prospects. New York: Routledge.

JOMO, K. S. (1998). “Malaysian débâcle: whose fault?” Cambridge Journal of Economics, 22, pp. 707-722.

JONES, C. J. (2000). Introdução à Teoria do Crescimento Econômico. Rio de Janeiro: Campus.

KALDOR, N. (1957). 'Conferências do Prof. Nicholas Kaldor.” Revista Brasileira de Economia, 11(1), pp. 3-99.

KAPLAN, E. \& RODRIK, D. (2001). “Did the Malaysian Capital Controls Work?” NBER Working Paper 8142, February.

KING, V. T. (1988). "Models and Realities: Malaysian National Planning and East Malaysian Development Problems”. Modern Asian Studies, 22(2), pp. 263-298.

KUZNETS, S. (1981). “Modern Economic Growth and the Less Developed Countries.” Conference on Experiences and Lessons of Economic Development in Taiwan. Taipei: Institute of Economics, Academia Sinica.

KUZNETS, S. (1985). “Crescimento Econômico Moderno: Descobertas e Reflexões.” Revista Brasileira de Economia, 39(2), pp. 141-240. 
KUZNETS, S. (1986). Crescimento Econômico Moderno: Ritmo, Estrutura e Difusão. São Paulo: Nova Cultural.

LIM, D. (1983). “Malaysian Development Planning”. Pacific Affairs, 55(4), pp. 613-639.

LUCAS, R. E. B. \& VERRY, D. (1999). Restructuring the Malaysian Economy: Development and Human Resources. New York: St. Martin's Press.

MISHKIN, F. (1999). "Lessons from the Asian Crisis." NBER Working Paper 7102, Abril.

MUSTAPHA, R. \& ABDULlAH, A. (2004). "Malaysia Transitions Toward a Knowledge-Based Economy." The Journal of Technology Studies, 30 (3), pp. 51-61.

NORTH, D. C. (1981). Structure and Change in Economic History. New York: Norton.

NORTH, D. C. (2005). Understanding the Process of Economic Change. Princeton: Princeton University Press.

RASIAH, R. (1993). "Free Trade Zones and Industrial Development in Malaysia”. In: JOMO, K. S. (ed.). Industrializing Malaysia: Policy, Performance, Prospects. New York: Routledge.

RITCHIE, B. K. (2004). "Politics and Economic Reform in Malaysia". William Davidson Institute (University of Michigan Business School). Working Paper Number 655.

VON DER MEHDEN, F. R. (1992). "Malaysia in 1991: Economic Growth and Political Consolidation”. Asian Survey, 32 (2), pp. 111-118. 